\title{
SOBRE $O$ AMOR E SUAS FALHAS: UMA LEITURA DA MELANCOLIA EM PSICANÁLISE
}

Felipe Castelo Branco

Felipe Castelo Branco

Psicanalista, doutor em Psicanálise pelo Programa de Pós-Graduação em Psicanálise da Uerj, formado em Filosofia (Ifcs/UFRJ) e em Comunicação Social (UFF), membro do Corpo Freudiano, seção Rio de Janeiro.
RESUMO: Pretendemos aqui analisar uma das definições que Lacan oferece da psicose (em 1975), atribuindo a uma falha do amor, em seu processo de constituição, a origem das psicoses de maneira geral. Após compreender o sentido dessa falha amorosa, buscaremos identificar o modo de operação do amor (e sua falha) no quadro clínico da melancolia.

Palavras-chave: Melancolia, amor, perda.

ABSTRACT: About love and its flaws: a reading of melancholy in psychoanalysis. This work's aim is to analyze one of the psychosis' definitions offered by Lacan (in 1975), attributing to a love's flaw of operation, the origin of psychosis in general. After understanding the meaning of this love's flaw, one will try to identify the operation of love (and its flaws) in the clinical condition of melancholy. Keywords: Melancholy, love, loss. 
«Parler d'amour, en effet, on ne fait que ça dans le discours analytique.»

(Jacques Lacan $)^{1}$

E m uma série de conferências proferidas em universidades dos Estados Unidos durante o ano de 1975, Jacques Lacan apresentou ao público norte-americano alguns dos principais elementos de seu pensamento e formulou em suas falas novas concepções, por vezes polêmicas, em relação aos temas sobre os quais refletia até aquela data. Deste modo, chegou até nós, oriunda da conferência do dia 24 de novembro de 1975 proferida na universidade de Yale, uma importante e frutífera definição da psicose, aparentemente inédita até então no ensino lacaniano. Citamos integralmente aqui essa definição lacaniana: "A psicose é uma espécie de falha no que concerne à realização disso que se chama 'amor.”. (LACAN, 1976, p.16) ${ }^{2}$

Refletir sobre essa passagem que nos parece tão fundamental, que une amor e psicose, é ao que nos dedicaremos nas próximas páginas. Nossa intenção, contudo, é buscar compreender se essa definição de Lacan pode contribuir para esclarecer alguns pontos acerca da melancolia. De início, nos perguntamo: como pensar essa espécie de falha que, por si só, já definiria, de certo modo, a psicose? O que, efetivamente, é perdido quando o amor falha em sua realização? Para tentar responder a estas questões que o comentário de Lacan nos propõe, em um primeiro momento investigaremos os possíveis modos de compreensão do amor na teoria lacaniana e usaremos, como recurso elucidativo, num segundo momento, a estrutura clínica da melancolia, buscando identificar a função que opera o amor no quadro melancólico e seus efeitos clínicos.

\section{DO AMOR}

Estamos em busca, portanto, de uma definição lacaniana do amor em psicanálise. Lacan jamais dedicou explicitamente um de seus seminários ao tema do amor. No entanto, além de retomar continuamente o assunto ao longo de sua obra; entre 1960 e 1961, seu ensino explorou o tema da transferência. Esta é uma maneira privilegiada de trabalhar o tema do amor, uma vez que, como é sabido, o amor é o motor da transferência. Mas Lacan vai ainda mais longe, chegando a declarar em mais de uma ocasião que transferência é amor (colocando-se em franca

\footnotetext{
1 “Falar de amor, com efeito, não se faz outra coisa no discurso analítico" (LACAN, 1972-1973).

2 "La psychose est une sorte de faillite en ce qui concerne l'accomplissement de ce qui est appelé ‘amour’”. Tradução livre. Meus mais sinceros agradecimentos ao Prof. Marco Antonio Coutinho Jorge por nos ter salientado a importância dessa passagem que se revelou tão frutífera em nossa pesquisa de doutorado.
} 
polêmica com aqueles psicanalistas que se dedicavam a teorizar sobre a chamada contratransferência).

Brincando com a famosa passagem bíblica que diz "no princípio estava o verbo", ele afirma que, no contexto da psicanálise, "no começo era o amor”, frase que dá título à introdução de seu O seminário, livro 8 - A transferência (LACAN, 1992). É nesse contexto que Lacan vai declarar haver certa dimensão de ensino própria à transferência. Se alguém se isola junto com outro nisso que pode ser chamado de relação analítica, é porque deve haver algo ali, na causa dessa relação, capaz de ser ensinado. Lacan se pergunta, em seguida: o que seria ensinado a esse que se submete à relação analítica? Resposta: o que lhe é ensinado é "aquilo que lhe falta” (LACAN, 1992, p.23). Tomando o amor de transferência como aquilo que nutre e dá esteio à experiência analítica, o que é ensinado pela transferência só pode ser transmitido, portanto, pela via do amor. Há uma ruptura radical entre a concepção de amor aqui desenvolvida pela reflexão lacaniana e àquela que Tomás de Aquino defendia na Suma teológica. Para este último, “amare est velle bonum alicui”, 3 amar é querer o bem a alguém. Lacan, por outro lado, empreende uma separação fundamental entre o amor e a ideia do bem. O amor de transferência - ou, ousaríamos dizer apenas, o amor — ensina àquele que ama que há uma falta inscrita em seu desejo. A própria natureza da transferência, portanto, como uma experiência amorosa, coloca em jogo a transmissão dessa falta que o analisando apreende amando. "Não estou ali, afinal de contas, para o seu bem, mas para que ele ame”, afirma Lacan (1992, p.23). E se há um amor fundamental que sustenta o laço entre analisando e analista, não há, no entanto, na relação analítica, um remetimento ao bem. O que se encontra ao fundo do amor transferencial não é o bem, mas uma suposição de saber por parte do analisando: suposição de saber do analista em relação a seu desejo.

Em suas reflexões sobre a ética da psicanálise, no ano anterior, o ensino lacaniano já havia se orientado, com alto rigor, contra a ideia de um Bem Supremo. O que uma psicanálise pode oferecer, quando toca a questão do desejo, é o confronto com o vazio no lugar onde supostamente residiria o Bem:

"A questão do Bem Supremo se coloca ancestralmente para o homem, mas ele, o analista, sabe que essa questão é uma questão fechada. Não somente o que se lhe demanda, o Bem Supremo, é claro que ele não o tem, como sabe que não existe. Ter levado uma análise a seu termo nada mais é do que ter encontrado esse limite onde toda problemática do desejo se coloca.” (LACAN, 1997, p.359)

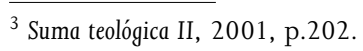


Desvinculado da relação tradicional com o Bem, o amor, para Lacan, mais do que um "querer" (como o identifica a leitura de Tomás de Aquino), é um oferecimento. O amante não é, precisamente, aquele que quer algo que se acrescente ao amado, mas é aquele que oferece ao amado sua própria falta. Acreditando ser o amado o detentor desse objeto precioso que falta a ele, amante, crendo ainda que o amado pode oferecer algum saber sobre seu ser (na transferência), o amante se oferece em amor, “pois é com essa falta que ele ama” (LACAN, 2005, p.122).

Mas é preciso compreender ainda de que maneira essa falta entra em relação no amor. Talvez a mais importante definição da operação amorosa em Lacan seja aquela que diz que "o amor é dar aquilo que não se tem" (idem). No entanto, a partir daí, é legítimo e até necessário perguntar: como é possível "dar” ao outro algo que falta a si mesmo? Resposta: sustentando, através do amor, uma carência que é o motor do desejo. Lacan brinca com esse ce qu'on n'a pas - modo de escrever em francês esse "dar o que não se tem" - lembrando que o a, do verbo avoir ('ter', em francês), é também o a do objeto que ele recentemente criara. ${ }^{4}$ Isto é, aquilo que se tem para oferecer no amor é justo uma falta, o que se dá é aquilo que não se tem. O uso da notação algébrica a possibilitou o manejo teórico desse vazio, nomeando o objeto da falta: objeto a.

É esse objeto da falta que entra em jogo no amor. O amor transforma imediatamente aquele que era objeto amado em sujeito amante, ou, dito de outro modo, o amor transforma aquele que ama em alguém que direciona sua falta ao Outro, isto é, o amante projeta, sobre o outro (amado), sua falta. A partir disso, a relação amorosa transmite uma incompletude que é colmatada pela promessa de união que o próprio amor oferece. Amar é oferecer em exposição à falta que o marca, é dar uma ausência que pede, ou melhor, demanda... demanda que é sempre, por definição, demanda de amor. Ao se perguntar se o objeto a é o objeto do amor, Lacan afirma que:

“ele o é na medida em que arranca metaforicamente o amante, para empregar o termo medieval e tradicional, do status em que ele se apresenta, o de amável, eromenos, para transformá-lo em erastes, sujeito da falta, mediante o que ele se constitui propriamente no amor." (2005, p.131-132)

Esse oferecimento da falta é precisamente aquilo que viria inaugurar a dimensão do amor. Ao falhar em sua realização, o amor falha em abrir o espaço desse oferecimento, o espaço de "circulação" da falta. Uma falha no que diz respeito

\footnotetext{
4 "Se a chama-se a em nosso discurso, não é apenas pela função de identidade algébrica da letra que pregamos outro dia, mas, por assim dizer, humoristicamente, porque ele é o que não temos mais. É por isso que esse a, que não temos mais no amor, pode ser reencontrado, pela via regressiva, na identificação, sob a forma da identificação com o ser." (2005, p.132).
} 
ao amor é, podemos adiantar, uma falha na transmissão desse impossível da relação sexual, ou seja, uma falha na função do objeto a.

\section{O AMOR E O GOZO: A DIMENSÃO NECESSÁRIA, CONTINGENTE E IMPOSSÍVEL DO OBJETO}

Antes de tentar compreender como opera essa falha na realização do amor que a frase de Lacan citada anteriormente atribui à psicose, precisamos destacar ainda outra dimensão do amor que não deve ser negligenciada. Numa famosa passagem de seu seminário de 1972-73 (Encore), Lacan nos diz que "o que faz suplência à relação sexual é, precisamente, o amor” (LACAN, 1975, p.59). ${ }^{5}$ Para além do oferecimento da falta que inscreve o amante como sujeito desejante na relação amorosa, o amor possui ainda uma função de suplência. 'Suplência' diz de algo que supre, que faz as vezes de alguma outra coisa. ${ }^{6}$ Sendo uma suplência à relação sexual, isto é, advindo como algo capaz de remediar a falha e a impossibilidade dessa relação, o amor, contudo, age em dois caminhos simultaneamente. Em uma primeira via, ele obriga o reconhecimento do furo, do vazio no seio da relação amante/amado, inscrevendo uma falta que aponta para uma instância Outra, fora dessa relação mesma: falar de amor supõe um sujeito, um objeto e algo mais-além do próprio laço amoroso (falo).

Numa segunda via, em que já se inscreveu o reconhecimento desse furo no seio da relação entre os amantes, o amor é também aquilo que mascara a inapelável pluralidade e indistinção dos objetos pulsionais. Dito de outro modo, não havendo uma ligação natural e necessária da pulsão a nenhum objeto específico, sendo todo e qualquer objeto "mundano" um potencial objeto eleito da pulsão e, de maneira análoga, nenhum objeto sendo efetivamente 0 objeto da pulsão, o lugar ocupado pelo objeto pulsional é o lugar de um vazio, de um cavo, uma abertura que não pode ser preenchida em seu ponto final. Em síntese: o objeto da pulsão é a própria presença da falta de um objeto, definida por Lacan como o objeto a. Não há, fica evidente, objeto algum que seja capaz de satisfazer plenamente a pulsão sexual. Portanto, uma escolha de objeto tem de se haver com a imensa pluralidade de objetos possíveis, sendo tais objetos o que há de mais variável e o que há de menos importante entre os elementos que compõem a pulsão, tal como se expressou Freud (1915/2010). Essa é uma dimensão absolutamente contingente da relação objetal. “A contingência é isto em que se resume o que submete a relação sexual a ser, para o ser falante, apenas o regime do

\footnotetext{
5 “Ce qui supplé au rapport sexuel, c'est précisement l'amour”, no original.

${ }^{6}$ Cf. ROCHA, Ruth. Minidicionário enciclopédico. São Paulo: Scipione, 1996. "Suplência sf:1. Ato de suprir." "Suprir v:1. Completar o que falta a. 2. Fazer as vezes de. 3. Abastecer; prover. 4. Remediar; acudir."
} 
encontro" (LACAN, 1975, p.120). Sendo contingente, esse nível se inscreve, portanto, na dimensão simbólica da escolha de objeto. É precisamente nessa dimensão de contingência que Lacan vai localizar a inscrição do Falo, isto é, nessa dimensão dos objetos é onde o Falo para de não se escrever. ${ }^{7}$ No entanto, esse domínio da variabilidade dos objetos será imediatamente "mascarado" pelos efeitos do amor.

O amor cristaliza imaginariamente uma escolha de objeto que, eleito entre a pluralidade e indistinção das coisas “amáveis”, aponta para uma suposta possibilidade de efetivação da relação sexual. Amar é também tentar fazer existir 0 objeto pulsional, fazendo apelo para que um objeto contingente se mostre necessário, suficiente e, o que é ainda mais fundamental, absolutamente indispensável para aquele que ama. É justamente essa aspiração que é manifestada pelas declarações dos amantes. Lacan não deixou escapar essa observação: "Nós somos um. É daí que parte a ideia do amor. É realmente a maneira mais grosseira de dar à relação sexual esse termo que escapa manifestamente, seu significado" (LACAN, 1975, p.61).

Enquanto a parcialidade da pulsão sexual evidencia essa fuga do "significado", isto é, enquanto o sexual tem de lidar com seu caráter parcial e contingente, o amor, por outro lado, aspira ao todo, à totalização. Tudo se passa como se aquilo que escapa ao contingente finalmente se escrevesse e, a partir de então, ele não cessa de se escrever. O amor encobre, portanto, o caráter contingencial das escolhas de objeto e busca naturalizar a ligação pulsional com aquilo que é amado, mascarando o contingente com o véu imaginário do necessário.

Contudo, se a dimensão imaginária presente no amor vela o caráter contingente da escolha de objeto em sua inapelável pluralidade, elegendo, por meio da escolha amorosa, um objeto que supostamente pudesse satisfazer de modo definitivo as exigências pulsionais; esse próprio caráter contingencial da escolha de objeto, por sua vez, já vela um aspecto ainda mais primordial da estrutura da pulsão: a impossibilidade estrutural da satisfação pulsional. É justamente aí que se situa a barreira da relação sexual: todo apontamento do sexual se direciona àquilo que não cessa de não se escrever: "O não cessa de não se escrever, ao contrário, é o impossível, tal como eu o defino pelo que ele não possa em caso algum se escrever, e é por aí que designo o que é da relação sexual - a relação sexual não cessa de não se escrever" (LACAN, 1975, p.120).

Sua satisfação pertence ao registro do impossível. E aqui se localiza a denúncia de Lacan do amor como sendo aquilo que vem em suplência à impossibilidade da relação sexual. O amor só aspira ao todo no momento mesmo em que, a partir da posição de amante, reconhece essa falta indelével que nutre toda escolha de

\footnotetext{
${ }^{7}$ Ou cessa de não se escrever, outra tradução possível para cesse de ne pas s'écrire (1975, p.120).
} 
objeto, esse vazio inscrito na estrutura. O Falo é buscado, portanto, enquanto ele é "o ponto extremo disso que se enuncia como causa do desejo" (idem), isto é, o objeto a.

\section{PERDA E MELANCOLIA}

Mas se Lacan afirma que a psicose é uma falha na realização do amor, como pensar essa falha amorosa na melancolia? De que falha o melancólico seria vítima?

O termo 'melancolia' representa, desde Freud, um quadro de perda. No entanto, a perda melancólica é, em sua aparência, uma perda incomum. O melancólico é alguém que permanece ligado a um objeto de amor de maneira patológica, mesmo após a morte ou perda definitiva desse objeto. Freud salienta que, na melancolia, o paciente é capaz de perder o objeto, mas jamais abre mão do laço que o liga ao amado. Esse laço que não cede e que permanece ligado ao lugar vazio deixado pelo objeto de amor indica-nos, de antemão, que não se trata, na melancolia, de uma escolha de objeto comum. Ainda que o luto possa apresentar por vezes, na clínica, um processo longo e de difícil elaboração, o que se passa após a perda do objeto amoroso na melancolia — apesar de algumas semelhanças fenomênicas com o luto - aponta para algumas diferenças profundamente radicais em relação a ele. A perda do objeto amado significa, para o melancólico, uma perda em seu próprio eu. O eu é quem sofre um empobrecimento e uma perda definitiva na melancolia. Há um laço inapagável muito fundamental entre a própria imagem narcísica do paciente melancólico — esvaziada, empobrecida e fragmentada no momento da perda do objeto - e aquele a quem o doente amava. Precisamos, portanto, compreender a origem do laço patológico do melancólico a seu objeto amado.

\section{O MELANCÓLICO E O OUTRO}

A chegada de uma criança ao mundo é marcada por uma indistinção entre o corpo do bebê e o primeiro Outro (por vezes, a mãe) que lhe dispensa cuidados. Esse Outro que o acolhe, se deseja a sobrevivência do pequeno humano recém-chegado ao mundo, deve buscar suprir algumas necessidades que o corpo do bebê requisita para permanecer existindo. A pequena criança, contudo, nessa relação, é colocada no lugar de objeto desses inúmeros e valiosos cuidados, sendo satisfeita naquilo que seu corpo demanda.

No entanto, para a psicanálise, aquilo de mais fundamental que uma mãe (o primeiro Outro do bebê) pode transmitir a seu filho, não são apenas os cuidados e carinhos dispensados a ele, mas sim um certo olhar que ama, acolhe e se direciona à criança, e que também, por outro lado, se encaminha em outra 
direção. O "deslize" da mãe para posições outras (mãe sim, mas também esposa, mulher, dona de casa, etc.) é profundamente salutar. É no vazio deixado pela mãe entre o clamor de seu pequeno filho (o choro que evoca a presença materna) e o atendimento de sua demanda (a chegada da mãe com seu seio) que a ligação mãe-bebê efetivamente nasce. Além disso, mãe deve ser aquela que é capaz de ler no "grito puro" [cri pur] do bebê - esse grito que não evoca nada além de uma insatisfação desarticulada —, um "grito para" [cri pour], isto é, ela deve receber esse grito puro lendo-o como uma possível demanda direcionada ao Outro:

“A mãe interpreta o grito como uma fala suposta à criança que ela coloca, desde seu
nascimento, em posição de sujeito-suposto-falante. Ela indica a recepção desse grito
e cria a hipótese de que ele quer dizer algo, que ele apresenta o sujeito ao mundo.
Reconhecemos aqui a definição do significante: aquilo que representa o sujeito
para um outro significante. O grito da criança não representa a criança para a mãe,
neste caso nós estaríamos no registro do signo; antes, ele representa o sujeito para
o conjunto de significantes a seguir. A resposta do Outro, a recepção que ele reserva
ao grito puro [cri pur] transformando-o em grito para [cri pour], vai transformar o
grito que se torna então significação do sujeito a partir do significante do Outro." (VIVÈS, 2006, p.303-317)

O significante do Outro, incluído pela mãe na interpretação do primeiro "significante" (grito) — lendo o grito do bebê como uma demanda — é o que vai representar o sujeito (bebê) como falante, para o Outro. É preciso, portanto, um duplo movimento do amor materno em relação ao bebê: a mãe deve ser capaz de se deslocar da posição exclusivamente materna, abrindo o espaço possível no qual a criança não será mais apenas um puro objeto de cuidados, e deve ainda, em seguida, ser capaz de ler no choro do bebê uma demanda em potência, ou seja, ela deve ser capaz de identificar no pequeno humano o que o psicanalista francês Jean-Michel Vivès chamou de sujeito-suposto-falante.

Em síntese: é por meio das ausências maternas, precisamente, que pode haver uma separação do bebê de uma posição de objeto colado ao corpo da mãe. E somente fora dessa posição de objeto do Outro materno é que o grito do bebê, como pura voz, pode ser lido como clamor, isto é, pode advir ao campo da simbolização. É preciso, portanto, que o Outro primordial, o primeiro Outro que recebe o bebê no mundo, seja capaz de faltar, de sustentar uma ausência capaz de introduzir uma abertura entre a criança e esse Outro: "o que desaparece [e falta] periodicamente, será destacável de um primeiro eu-mundo indiferenciado" (LE POULICHET, 1994, p.20). Em suas ausências, a mãe é capaz de transmitir uma falta a um ser que pode, a partir de então, ter a abertura de se ver como faltoso (condição para tornar-se sujeito), e não mais permanecer na posição 
de algo lançado à mercê dos caprichos e do gozo do Outro (correspondente à condição de objeto). Se o seio falta, instaura-se uma perda que é condição para o advento do sujeito. É nesse contexto de adiamento da satisfação das demandas do corpo do bebê que surge o vazio entre o desejo e seu objeto. Esse adiamento corresponde à uma possibilidade de abertura:

“[ele abre] a lacuna onde se alojará o objeto. [Põe] em jogo a ausência que fundamenta o fora. E é realmente esse fora que, como tal, faz surgir a perspectiva de um dentro. Esse processo, que estaria na base da temporalidade psíquica, faz advir a presença sobre o fundo de uma ausência [...]”. (LE POULICHET, 1994, p.20)

Ora, como salienta Lacan (1997), se é o seio que falta na perda instaurada pelo amor e pelo acolhimento materno, não é propriamente o seio, contudo, que vai dar ensejo ao advento do desejo — será a falta propriamente. Falta essa que não é especularizável, mas que, no entanto, Lacan batizou de objeto a. Se é o seio que funda essa primeira experiência de perda, se é o seio que possibilita um primeiro destacamento da falta mascarada na ausência, é o objeto a, como objeto faltoso, que poderá se alojar nessa hiância. O objeto a, sendo irrepresentável e sem imagem, requer o uso de experiências corporais de perda (seio, fezes, etc.) para representar psiquicamente a falta. A perda mais fundamental (da Coisa), perda que instaura o lugar do objeto a, só pode se presentificar para o sujeito sendo mascarada, num primeiro momento, de perda do seio:

\footnotetext{
“Esse elemento não representável [e que, no entanto, toma representação no seio, por exemplo] é talvez a percepção mais próxima que se pode ter do objeto perdido. Lacan nomeou isso o objeto a - um ponto de perda que escapa à visualização ou à representação direta. Para aprendê-lo, ele pensava, usamos de nossas próprias experiências corporais de perda, como meios de situá-las psiquicamente. Associamos inconscientemente separações, ligadas, por exemplo, à alimentação e à excreção com a dimensão essencial da perda estabelecida nas nossas primeiras relações com a mãe. Como o seio e o excremento são separados de nosso corpo, eles podem servir para encarnar a ideia de uma perda, a lhe dar consistência. Esses elementos vão, assim, ocupar o lugar do objeto a, e terminar por organizar o campo de nossos desejos." (LEADER, 2010, p.145)
}

A partir do que acabamos de verificar, é importante dar destaque ao fato de que a perda do seio, ainda que seja uma experiência fundante para o sujeito a advir, tem como vetor inicial, antes de tudo, o Outro materno. É a mãe, em seu oferecimento amoroso, quem perde o seio. Se a falta inaugurada por essa primeira experiência de perda vai ser capaz de organizar o campo do desejo do 
sujeito, o Outro materno, por sua vez, deve ser capaz de acompanhar o pequeno bebê na experiência de desmame. É ele quem deve ceder o seio (permitindo a saída da posição de objeto) e ler no grito puro do bebê uma carência, uma falta que demanda simbolização (advento do sujeito). O amor materno é esse amor que cede, que permite um “espaço de respiração” entre o sujeito-suposto-falante (o bebê como sujeito a advir) e o Outro materno. E é nesse espaço onde a falta virá se alojar.

Jacques Hassoun (2002) aposta na hipótese de que o melancólico é vítima da impossibilidade de o Outro materno sustentar um desmame. Sendo interditada a perda do seio pelo Outro na melancolia, o sujeito permanece agarrado, preso a um gozo movediço que o impede de se distanciar de um Outro sem barra. Afundado nesse gozo, torna-se impossível, entre o sujeito e o Outro, a queda de um objeto que, como evidência da falta e distanciamento de das Ding, possa causar seu desejo. Cito Hassoun: "Podemos dizer, desde logo, que a criança só pode ceder aquilo que se constituiu como perdido pelo Outro. É nessa operação que o objeto se constitui" (2002, p.45). Ora, o objeto depende desta perda que abre um furo no primeiro Outro para se constituir. Dito de outro modo, o objeto é, precisamente, o resultado de o Outro não deglutir o sujeito por inteiro, num gozo devastador.

Para pensar com Freud: seria mais econômico, é evidente, que a criança se mantivesse numa unidade amorosa absoluta com a mãe, gozando de seu corpo, alimentando-se dela e ainda, posteriormente, apontando seus impulsos sexuais em direção àquele que é o primeiro Outro do qual ele obteve o carinho e os cuidados fundamentais para sua sustentação vital. Não é natural que alguém que seja alimentado, cuidado, limpo, amado e protegido num laço dual fortíssimo, queira buscar fora dessa relação seu objeto sexual. Contudo, algo se dá no caminho dessa relação tão totalizante. Algo barra o acesso integral do bebê ao corpo da mãe. Sendo interditado pela Lei fundamental da interdição do incesto, o sujeito entra no campo simbólico e terá de buscar satisfação em objetos existentes fora dessa relação absolutizada. Mas, o que é o mais fundamental, é que essa proibição é apenas a expressão simbólica do que é precisamente impossível, a saber: essa coincidência perfeita, esse gozo absoluto, isto é, a relação sexual. A mãe que ama é a mãe que oferece carinho, cuidados e acolhimento, mas é também uma mãe que transmite sua falta e que tem de buscar satisfação em outros objetos fora da relação mãe-bebê. O Outro também tem de ceder, também revela, no amor, a sua precariedade, sua falta. Incapaz desse amor, o Outro da melancolia não permitiu que o objeto a ganhasse um registro psíquico. O melancólico advém exatamente do limite onde o amor falha em sua realização. 


\section{O AMOR MELANCÓLICO}

Mas que tipo de amor o melancólico nutre pelo objeto perdido? Retornamos à questão da perda do outro amado, e do laço profundo que existe entre o objeto e o eu na melancolia. A perda do objeto é, para o melancólico, uma perda fundamental e que atinge diretamente sua imagem especular. Como afirma Freud (1917/2010), o melancólico sabe quem ele perdeu, mas não é capaz de saber o que ele perdeu nesse alguém amado. "Na melancolia não se pode saber o que em si (o ‘si mesmo' do 'eu’) foi perdido, nem o que de si foi perdido com o objeto. Essa perda enigmática que afeta o eu, permanecerá desconhecida a este último" (DIAS et al., 2008, p.32).

O melancólico parece ter sido vencido pelo vazio deixado pelo objeto. No entanto, antes mesmo de buscar saber o que o sujeito perdeu na melancolia, é preciso tentar saber o que, anteriormente, ele possuía em sua relação com aquele a quem amava. A autoimagem do melancólico, destruída no momento da perda daquele a quem ele amava, nos fala, a partir da fina observação freudiana, da dependência que faz da relação melancólico/objeto uma cola imaginária. Não há separação entre a melancolia e seu objeto: o eu é o objeto. É por tomar o objeto amado como seu eu ideal, i(a), que o melancólico ama e ao mesmo tempo permanece dependente de sua imagem. Esse objeto amado se fez de apoio imaginário que deu suporte à própria imagem narcísica do melancólico e, por isso, quando do momento da perda, o choque com o vazio deixado pelo objeto coloca o melancólico “sem chão”, esvaziado daquela imagem que ele buscava no outro como sua:

“o melancólico está condenado ou a errar à margem de seus irmãos ou a agarrar-se a sinais de reconhecimento que ele teria elegido em um deles. Por isso, quando este referente é levado a desaparecer, o melancólico vê-se remetido ao vazio de sua identidade e ao mero recurso do canibalismo arcaico”. (LAMBOTTE, 2000, p.41)

O amor pelo objeto na melancolia é o mais primitivo porque ele está sustentado não numa escolha de objeto propriamente, mas numa identificação que mimetiza a imagem do outro, e “cola” o melancólico ao objeto. Quando da perda do outro na melancolia, aquela relação necessária que funcionava como bengala imaginária para o melancólico pende diretamente para o campo do real, com sua evidência de impossibilidade. O melancólico vai de uma relação amorosa radical (de profundo amor ao objeto), para uma queixa de profunda sensação de vazio, indiferença e desprezo pela existência das coisas e pessoas em seu entorno - o que é a expressão mais crua da total retirada da libido, ou seja, a força sexual da pulsão, de todo e qualquer objeto do mundo. Sem a possibilidade de lidar com o objeto que falta no Outro, o melancólico não é capaz de se interessar por pessoas 
ou coisas, mas pode apenas lamentar aquilo que nunca possuiu: um vazio que mantivesse o laço que o permitiria apegar-se à vida. Sem o vazio fundamental do objeto, não há amor por outros objetos, senão o amor patológico nutrido por aquele ao qual o eu melancólico se fundiu.

\section{LUTO, MELANCOLIA E A FALTA}

Se pensarmos, assim como fez Freud, no luto como algo comparável à melancolia, entenderemos que o luto é um processo que marca uma separação radical. Que separação é essa? A separação entre o objeto que foi perdido, aquele ente amado que se foi definitivamente, por um lado, e o lugar que ele ocupava para o enlutado, por outro. O luto é um processo que busca, em última instância, distinguir o envelope narcísico do objeto, daquele vazio que permanecia recoberto por sua imagem.

“Esse ato pode se assemelhar ao grande sacrifício edipiano que estrutura nossa
infância: a renúncia à mãe para obter acesso aos outros. E talvez seja preciso perla-
borar e o colocar em cena em cada luto. Os sacrifícios reais, empíricos, funcionarão
então como metáforas desse processo mais fundamental.” (LEADER, 2010, p.148)

Tendo vivido o processo fundamental de perda, quando o Outro materno cede o seio permitindo ao pequeno infans viver a experiência da falta, o enlutado "reatualiza" as coordenadas dessa perda fundamental em cada processo de luto. O luto é, portanto, um processo que faz da perda de alguém amado uma fonte de elaboração da falta essencial da estrutura. A perda do luto é, acima de tudo, uma perda da imagem que funcionava como envelope imaginário para a falta de objeto (o objeto a). O objeto perdido no luto coloca em relevo a falta primordial de um objeto específico da pulsão. E é nesse confronto direto com a falta que se torna possível que, no futuro, o enlutado dirija seu amor, mais uma vez, a um novo objeto. Ao fim desse processo doloroso, o sujeito em luto será capaz de reconhecer que outro objeto pode ainda ocupar o lugar vazio deixado por aquele que foi perdido, recompondo novamente uma imagem para velar essa falta sem imagem, não especular.

Na melancolia, contudo, não há inscrição dessa perda que cria o vazio do objeto. Dito de outro modo, o melancólico é refém de uma falha do amor do Outro que, ao acolhê-lo, não possibilitou a inscrição de sua falta, ou seja, não criou a possibilidade de um desmame. O amor do Outro primordial falhou em sua função de produzir esse vazio lógico ao qual toda escolha objetal viria posteriormente operar como recobrimento. A melancolia padece, portanto, de uma falha fundamental: a falta da falta. Por essa razão, a perda do objeto amado, 
para o melancólico, não abre a possibilidade de elaboração da falta fundamental, como no luto. Sua perda é ainda mais radical. Na melancolia há uma perda sem falta. Uma perda que não remete à perda originária da Coisa, e que, portanto, é vivida como uma perda radical, sem precedentes e sem amparo simbólico. Ao desaparecer o objeto amado, o melancólico mergulha novamente num gozo sem falta (eis aí a falta da falta). Impossibilitado de participar do nível contingente dos objetos - plano do sexual, que tem como horizonte a falta de objeto, jamais inaugurada na melancolia —, o melancólico agarra-se a seu objeto de amor, numa transitividade imaginária que impede qualquer separação. O eu é o objeto. Porém, ao perder esse objeto de amor, sua queixa passa diretamente do plano do necessário e da transitividade ao plano do impossível. Sem a mediação do sexual, isto é, do contingente (plano no qual o luto se sustenta para reelaborar sua perda), o real transborda para fora da compacidade da falta de objeto, e o melancólico fica remetido, sem mediação, ao impossível, ao real. Freud traduziu essa constatação afirmando, em $\mathrm{O}$ eu $e \mathrm{o}$ isso, que na melancolia há uma radical dessexualização da pulsão. E o efeito disso seria "cultura pura da pulsão de morte" (FREUD, 1923/1996, p.54).

Mesmo em meio ao sofrimento pelo desaparecimento definitivo do objeto, o paciente é incapaz de abrir mão daquele amor que ele nutriu (e que também o nutria, como sustentação de sua própria imagem), e passa a manter esse amor, ainda que sem a presença do objeto, como uma ferida aberta exposta em sua fala: eis o preço pago por um laço amoroso sem objeto. Sem a inscrição lógica da falta na qual todo objeto amado deve ocupar o lugar, o melancólico é incapaz de fazer um luto de sua perda: não se trata, na melancolia, de um luto sem fim, mas, mais precisamente, da completa impossibilidade de executar qualquer processo de luto. Vítima de uma falha naquilo que o amor pode realizar, o melancólico, esse não amado pelo Outro, é, também por isso, incapaz de separação (do Outro). Ou, nas palavras de Jacques Hassoun: "O melancólico é esse objeto não separado que não chegou a ser.” (2002, p.48).

Se nos tornamos um pouco loucos quando amamos, por outro lado, o próprio amor é aquilo que, a seu modo e paradoxalmente, pode nos oferecer esse laço salutar e profundo "que faz todo vivente se apegar à vida", como disse Freud (1917/2010, p.172). Concluo com uma belíssima frase de João Guimarães Rosa, aparecida em Grande sertão: veredas, e que me causou a fortíssima impressão de que em uma única linha, é capaz de dizer mais e melhor do que me foi possível em todas essas páginas: "Qualquer amor já é um pouquinho de saúde, um descanso na loucura" (2001, p.327).

Recebido em 29/1/2011. Aprovado em 16/8/2011. 


\section{REFERÊNCIAS}

AQUINO, T. (2001) Suma teológica II. Ed. bilíngue. São Paulo: Loyola.

DIAS, C. et al. (2008) L’abandon, l'autre nom de la mélancolie freudienne, in Essaim, Revue de Psychanalyse. Paris: Érès.

FREUD, S. Obras completas. São Paulo: Companhia das Letras.

(1917) "Luto e melancolia", v.12, p.170-194.

(1915) “Os instintos e seus destinos”, v.12, p.51-81. . (1996) Obras completas. Buenos Aires: Amorrortu. (1923) “El yo y el ello", v.XIX, p.13-66.

HASSOUN, J. (2002) A crueldade melancólica. Rio de Janeiro: Civilização Brasileira.

LACAN, J. (1976) Conférences et entretiens dans des universités nord-américaines, in Scilicet, 6(7), Paris: Seuil. (1997) O seminário, livro VII - A ética da psicanálise. Rio de Janeiro: Jorge Zahar.

(1992) O seminário, livro 8 - A transferência. Rio de Janeiro: Jorge Zahar.

(2005) O seminário, livro 10 - A angústia. Rio de Janeiro: Jorge Zahar. (1975) Le séminaire, livre XX - Encore. Paris: Seuil.

LAMBOTTE, M-C. (2000) Estética da melancolia. Rio de Janeiro: Companhia de Freud.

LE POULICHET, S. (1996) O tempo na psicanálise. Rio de Janeiro: Jorge Zahar. LEADER, D. (2010) Au-delà de la depression: deuil et mélancolie aujourd'hui. Paris: Payot \& Rivages.

VIVÈS, J-M. (2006) L’avocation mélancolique. Cliniques méditerranéennes. 73, Toulouse: Érès, 303-317.

ROSA, J. G. (2001) Grande sertão: veredas. Rio de Janeiro: Nova Fronteira.

Felipe Castelo Branco

felipecastelobranco@terra.com.br 